\title{
ANTROPOGÉNESIS: CONSIDERACIONES BIOHERMENÉUTICAS ${ }^{1}$
}

\author{
Carlos CASTRODEZA \\ Departamento de Logistica y Filosofia de la Ciencia, \\ Facultad de Filosofia, Universidad Complutense, 28040 Madrid
}

\section{Resumen}

En la época actual, desde la ciencia, tenemos una idea de nuestro origen relativamente contradictoria. Por un lado, al parecer, somos animales, pero por otro lado, no es así. Una manera de decirlo es que seríamos animales especiales. La idea, desde las humanidades, y/o desde un pensamiento que pretende ser ciencia sin serlo (pseudociencia), es que el hombre es un ser único y superior por obra y gracia de, al menos, su propia conciencia. Pero claro, la diferencia entre la ciencia y sus imitaciones no es algo nítido, especialmente si se contempla todo como un proceso, como una perspectiva desde la historia de la ciencia, por lo que, al respecto, navegamos en aguas de dudosa identidad. Las especulaciones sobre un origen biológico del hombre empiezan a tomar su forma actual en la época del Despotismo Ilustrado y adquieren un impulso ya sobresaliente con Darwin. Pero la noción sobre el origen animal del hombre es

1 Por biohermenéutica entiendo el estudio de una dimensión propiamente biológica ("darwiniano-freudiana") de los aspectos más intrínsecamente humanos que posiblemente encuentren su expresión más idónea en los existenciarios Heideggerianos (véase, por ejemplo, el artículo de Richard COYNE "Cyberspace and Heidegger's pragmatics" en Information, Technology and People, vol 11-4, 1998, sin paginar, o el texto de Samuel B. SOUTHWELL, Kenneth Burke and Martin Heidegger: With a note against deconstruction, University of Florida Press, Gainesville, 1987). Asimismo, existen paralelismos metodológicos, que no coincidencias epistémicas, en otras aproximaciones biohermenéuticas como puedan ser la de Kalevi Kull (véase "Biosemiotics in the twentieth century: a view from biology", Semiotica, 127 (1999), pp. 385-414) y especialmente la de S. V. Chebanov ("Biohermeneutics and the hermeneutics of biology", Semiotica, 127. (1999), pp. 215-26). 
traicionera, porque el hombre desaparece como algo especial, ya no se "origina", o si lo hace se reafirma como lo harían, por ejemplo, un león, un delfín, un ratón, un helecho o un ciprés. Y en cualquier caso su controvertida "aparición", como la de cualquier otro ser vivo, lleva aparejada la posibilidad de su desaparición, de su extinción, y no precisamente por medio de un cataclismo, sino, sin ir más lejos, por selección natural. Pero si la ciencia es nihilista, la reacción ante la ciencia también lo es. El problema central es que el hombre se recrea como anomalía orgánica, huyendo de su propio medio, de su propio destino, huyendo así hacia una cierta inautenticidad orgánica: ésta sería la clave del hermetismo heideggeriano, hermetismo que, paradójicamente, se evidencia claramente desde la perspectiva darwiniana.

\section{Introducción personalizada}

Desde que el hombre es hombre ${ }^{2}$, éste se interesa por su origen y su destino. Es como si las dos preguntas estuvieran enlazadas. Porque, de alguna manera, personalizando, puedo haber vivido en cualquier época o lugar, y lo que ha propiciado mi origen puede dar al traste con mi existencia. Así, en abstracto, si me ha creado "alguien" o "algo", ese "alguien" o ese «algo" puede acabar conmigo, todo ello por razones que en principio se me escapan. Y si he aparecido por casualidad, puedo desaparecer del mismo modo, y ahora ya no hay razones aunque haya causas. Pero si saber quien soy, es decir, la intelección de mi origen, situación presente y desenlace ulterior, es una cuestión que exige réplica, quizá existe una prioridad en esa intelección, que es averiguar dónde estoy, aquí y ahora. Para contemplar mi existencia, en su origen y desenlace, tengo que tener una seguridad mínima de que no estoy soñando, ni inmerso en una realidad virtual que se me antoje real. $\mathrm{O}$, al menos, que esté donde esté, sea la realidad que me acoge verdadera o ficticia, debo sentir una seguridad mínima sobre mi identidad, en el tiempo

2 Desde luego, esta aserto no deja ser retórico en buena medida, porque la naturaleza humana es indefinible no ya desde una perspectiva, por ejemplo, existencial, ontológica en general, sino simplemente desde un punto de vista biológico (véase el artículo "Human Nature" de D. Hull en Philosophy of Biology, comp. de M. RUSE y D. Hull, Oxford University Press, 1998). Es más, esta indefinición de la naturaleza humana muy posiblemente, y un tanto paradójicamente, tiene su raíz actual en una creencia a ultranza de la esencialidad humana, noción renacentista que proclama que la actuación humana no está constreñida al completo por las leyes naturales y por lo tanto es indefinible en el sentido de inefable (la fuente clave seria, claro está, el De hominis dignitate oratio de Pico della Mirandola). 
(antes, ahora y después) y en el espacio (aquí y allí), para poder pensar y percibir hasta que punto puedo dar contestación a lo que perturba mi autoconciencia ${ }^{3}$.

Pero no estoy solo en el mundo. Están mis congéneres que son y han sido. $Y$ son muchos los que han sido. Y muchos de ellos han dejado legados con sus respuestas y las de sus semejantes que también lo son míos. Muchos de esos legados ya no son convincentes porque la historia los ha ido algo así como dejando de lado, al menos parcialmente. Otros legados siguen siendo sugerentes, especialmente los de otros muchos de mis congéneres actuales que han hecho balance y tienen propuestas de última hora. Por añadidura, claro, cualquiera de nosotros, yo mismo, además de espectadores somos actores en estas lides, en mayor o menor medida. Me interesa entonces aunar todas estas situaciones, ver por mí mismo, porque nadie puede sustituirme en mi trayecto vital, concretamente en su apabullante final. Antes de morir, curiosamente, necesito "saber" " ${ }^{4}$. O sea que para seguir viviendo mal que bien necesito «saber». Requiero, en última instancia, experimentar por mí mismo, al menos en algún momento, la sensación de que sé, aunque únicamente sea ese "sólo sé que no se nada" socrático ${ }^{5}$.

En definitiva, preciso conocer mi historia, el principio posible y el final previsible, poseer al menos una síntesis de lo que pensaron en esta línea los que me han precedido, y lo que piensan sobre la cuestión los que viven conmigo. Necesito, trivialmente, para saber ¿qué es el hombre?, o sea, ¿quién soy yo? contestarme una vez más, y constantemente, en clave kantiana ¿qué puedo saber? ¿cómo debo vivir? ¿qué puedo esperar? todo ello al respecto de mi origen y mi destino ${ }^{6}$.

3 Aunque éstas sean las preguntas "de siempre" presentadas con cierto tinte cartesiano, la intención es contextualizarlas no ya dentro del naturalismo más actual, de corte darwiniano, sino dentro de un metanaturalismo de inspiración heideggeriana (para más detalles se podrá consultar mi próximo «Hacia una hermenéutica evolucionista: del naturalismo darwiniano al metanaturalismo heideggeriano" en Diálogo Filosófico, véase también "Hermeneutik oder Naturalismus?" de A. STEPHAN en Psyche 47 (1993), pp. 425-40 y, especialmente, "An «irreducible» component of cognition" de Massimo PiaTELli-PALMARINI, capítulo 18 de Thinking about Evolution: Historical, philosophical and political perspectives, compilación de Rama S. SingH y otros, Cambridge University Press, Cambridge, 2001).

4 Esta curiosidad deja de ser sorprendente desde la tesis del gen, en cuanto replicador, como unidad de selección, porque entonces mi identidad es algo delegado y enteramente reducible a esas estructuras más elementales.

5 Esa propensión a "saber» (tan aristotélica por otra parte), en el sentido de al menos querer conocer el propio medio es algo, conviene tenerlo en cuenta desde un principio, extensible a todo ser vivo, independientemente de que se haga de un modo instintivo o no.

6 Trivialmente, en el sentido, cabe decir, más orteguiano del término, puesto que un ser consciente, no ya de sí mismo sino de su propia historia (lo que, argüiblemente, viene a ser lo 
Claro está que, por otra parte, soy una persona de mi tiempo y lugar, y creo con cierta firmeza que sé que mi origen y mi destino no son acontecimientos $\mathrm{ni}$ misteriosos ni que me "vayan a sacar de apuro». Sé, creo saber, por mi tiempo y lugar, que la "suerte está echada", que mi origen es un accidente y que no tengo destino ${ }^{7}$. Pero ¿por qué a pesar de ello deseo vivir y quiero saber más, así, «como si nada" 8 ? No sé, aunque "crea saber", y lo quiero saber. Entre otras razones, no me agradan las contestaciones de mi tiempo y lugar, aunque me sienta desagradablemente convencido. En cualquier caso quiero conocer como he (hemos) llegado a esta situación, los que como yo, de alguna manera, nos ponemos en el peor de los casos, en el caso de aquéllos "que saben que lo que creen que saben" es irrelevante para tener una buena vida, lo que han buscado "los filósofos de siempre». Se trata de matizar, por qué, de todos modos, se debe vivir una buena vida "contra el peor viento y la marea más adversa", aunque lo único que se pueda esperar sea no tener que empujar la roca de Sísifo por segunda vez, o más veces, al menos que "uno recuerde" o pueda en un futuro fantasear/dilucidar 9

\section{El marco de la realidad (La plataforma epistémico-histórica establecida)}

\section{La cuestión centrada desde Grecia al Barroco...}

Así las cosas, las teorías sobre la aparición del hombre son múltiples y variadas ${ }^{10}$. Por otra parte, existe en la actualidad una división no enteramente clara

mismo, a pesar de estados patológicos que merman la memoria orgánica), considera esa historia como parte de su propio medio que, claro, entra en el "territorio" que hay que conocer. Tampoco es suficiente, contestar en vena heideggeriana, que el hombre es el ser que se hace esas preguntas, aunque sí entra dentro de lo posible que no se pueda ir más allá de esa contestación sin introducirse en "especulaciones sin salida".

7 Claro está que aunque esta concepción sea generalizable goza de importantes excepciones (véase por ejemplo el texto reciente del conocido bioantropólogo Ian TATTERSALL, The Monkey in the Mirror: Essays on the science of what makes us human. Harcourt, Nueva York, 2002).

8 De nuevo, desde la teoría del gen, como unidad de selección, "yo" no sería el beneficiario real del conocimiento, sino, simplemente, un depositario pasajero.

9 Situación negativa desde la perspectiva de un Camus, pero no así de un Nietzsche, por eso, ineludiblemente, hay que matizar.

10 La cuestión se puede complicar extraordinariamente si nos tomamos en serio, por ejemplo, la idea foucaultiana de que el hombre como sujeto autoconsciente es una invención del siglo XVIII, y más todavía si al decir de, por ejemplo, Lacan, la realidad de la autoconciencia es algo puramente imaginario. Por lo tanto, de alguna manera puede que nos movamos en una 
al respecto de diferenciar entre lo que generalmente se denominan explicaciones míticas y explicaciones científicas. Obviamente, las explicaciones míticas están encuadradas en esquemas pre-teológicos o teológicos propiamente dichos, al menos en un sentido coloquial. Mientras que las explicaciones científicas eliminarían la intervención de fuerzas intencionales más o menos personalizables. El problema, como aparece, no es ya que la delimitación en cuestión no esté clara, sino que ésta se constituye en la práctica en una zona intermedia, mítico-científica, cuya delimitación es difusa. Por ejemplo, se puede decir que la separación entre el día y la noche no está clara aunque sí lo está lo que es día y lo que es noche. Bueno, pues lo mismo no se puede decir de las explicaciones científicas y las que no lo son. De manera que no sería fácil distinguir en última instancia entre una explicación propiamente científica y otra pseudocientífica, especialmente en la tesitura contemplada, salvo en casos especialmente extremos donde ya nadie está epistémicamente cómodo ${ }^{11}$.

Pero hagamos, para situarnos, una breve proyección histórica, rápida pero enjundiosa en lo posible, de lo que pudieron ser nuestras propias raíces desde tiempos relativamente recientes.

En ese proceso de secularización incipiente que se plasma en la Grecia clásica, según el presocrático Anaximandro, el hombre procede del mar de un modo cuasi-evolutivo. Mientras que su casi coetáneo Empédocles supone que, en una creación original, a partir de ciertos elementos (aglomerados indiscernibles) se forman todas las combinaciones posibles, y las que son viables (minerales, rocas, animales, plantas, hombres) permanecen y las demás (quimeras varias) no prosperan, no encajan y se desintegran. Esto vendría a ser como un proceso de selección natural un tanto tosco por lo acelerado. Por otro

ambigüedad un tanto derrideana, porque biológicamente hay una especie Homo sapiens sapiens que habría adquirido carta de naturaleza en "algún momento" de la historia de la vida, pero por otro lado no hay seguridad en que la reconstrucción del origen de esa especie obedezca a los patrones naturalistas vigentes, de modo que "en el mejor de los casos» una proyección metanaturalista parece inevitable.

11 En los mejores tiempos del positivismo lógico, cuando la escena estaba bajo el dominio de Carnap, una actitud, digamos cientificista, podía "dar el pego", pero después, con Quine, y, mucho más, con Davidson, esta situación es muy difícilmente sostenible. Recuérdese también una de las expresiones más reveladoras del archi-racionalista Karl Popper al referirse al proceso científico como "mitología crítica". Igualmente, desde las Mitologicas de Lévi-Strauss, la estructura del mito, o de la teoría, sólo sería un reflejo de la estructura cerebral del hombre lo que nos conduce a un círculo un tanto hermenéutico. 
lado, para los socráticos Platón y Aristóteles, la intervención de una divinidad relativamente poderosa (un demiurgo generalizado) en la creación del hombre estaría bastante clara para el primero y relativamente clara para el segundo. Mientras que para los helenísticos, o pos-socráticos, esa mezcla de explicaciones y pseudoexplicaciones, indisociables las unas de las otras, tienen otras derivaciones. Así, por seguir cotejando opiniones bien conocidas, para los epicúreos todo lo que existe son combinaciones de átomos, igualmente más o menos viables - lo que está en la línea de Empédocles- incluso los dioses se habrían originado/estarían constituídos así, sean éstos pocos o muchos. Para los estoicos, en cambio, todo está determinado por leyes naturales, por lo que todo existe por necesidad, de manera que la aparición del hombre sería algo asumible en ese contexto cósmico. Los escépticos en cambio no sólo no se animan a construir teorías sino que tratan de contaminar con su escepticismo a los otros, sobre todo a los estoicos. Para ellos, en el más depurado espíritu sofista, toda idea sería, en el mejor de los casos, como un instrumento para conseguir ciertos fines. En resumen, unos creen y otros creen que no creen. Pero sigamos inventariando sin excesos en aras a una posible traca final ${ }^{12}$.

Claro, para las mitologías, tanto griega como pre-romana y luego romana, que conviven en parte con el pensamiento pre-racional de presocráticos, socráticos y pos-socráticos, la aparición del hombre sería algo así como un accidente mítico. Incluso habría seres híbridos entre hombres y dioses y, por supuesto, aunque en menor escala, entre animales, dioses y hombres.

Luego, en la versión judaica y derivaciones islámica y cristiana, como bien se sabe, Dios le crea al hombre a su imagen y semejanza de un modo peculiar en lo que ya es un origen genuino. Origen en un principio con un destino abierto, pero que al corromperse el hombre en un pecado, asimismo original, da lugar a la historia de la condición humana que se plasma, en una de sus dimensiones, en la generación de preguntas ácidas y respuestas desconcertantes. En lo que llamamos Occidente, la versión cristiana es prácticamente la única que se impone socialmente, descontando los reductos paganos varios que van desapareciendo hasta prácticamente la llegada del Renacimiento (aunque, la teología cristiana en sus detalles tenga una buena dosis platónica

12 Claro debe estar, que en la Grecia clásica al no existir una idea evidente de direccionalidad histórica, toda cuestión relativa a un "origen" se incluye, en el mejor de los casos, en un relato cíclico, y, en el peor de los casos, pierde toda significatividad. 
en un principio, aristotélica después, e incluso hermética —dionisíaca一, en buena parte de esa historia antes de bien entrado el Barroco).

\section{...y desde el Barroco a nuestros días}

Como igualmente bien se sabe, con el Renacimiento hay una supuesta repaganización de la cultura occidental que en gran medida es ficticia salvo en personajes como Thomas Hobbes o el menos conocido Francisco Sánchez (15501623). Digo que es ficticia porque bien conocidos episodios como el conflicto entre Galileo y la Iglesia de Roma no tenían otra base aparte de cuestiones estrictamente doctrinales afines y no ajenas al cristianismo, como asimismo ocurriría con Giordano Bruno en su colisión con la inquisición del Papa Clemente VIII y el gran inquisidor Roberto Belarmino, o entre Miguel Servet y el tribunal ginebrino de Calvino. Es decir, la cosmología cristiana de Galileo tenía matices platónico-pitagóricos muy intensos que competían con la interpretación aristotélico-tomista de la Iglesia Romana más ortodoxa. De la misma manera que las disidencias de Lutero, Calvino y otros heterodoxos, con respecto a la Iglesia de Roma, también eran obviamente teológicas, al menos en su presentación de cargos contra Roma. Igualmente, la disidencia manifiestamente heterodoxa por parte de filósofos naturales ingleses, como el denominado padre de la química moderna, Robert Boyle, o el "gran" Isaac Newton, con la citada iglesia romana también era estrictamente teológico-política. Esta vez, estos científicos del alba de la modernidad, bastante al unísono con el francés René Descartes, encubrían con su doctrina mecanicista una versión cristiana del atomismo epicúreo apoyada y matizada epistémicamente dentro del mundo católico, quizá con especial énfasis, por los frailes franceses, siempre ortodoxos en su forma aunque quizá dudosamente en su intención (al igual que Descartes), Marin Mersenne (1588-1648) y Pierre Gassendi (1592-1655).

Sin embargo, la paganización mencionada adquiere una dimensión ya no tan claramente ficticia en la ilustración, especialmente en las ilustraciones escocesa y francesa. Además, es una paganización epicúrea en cuanto a la irrelevancia de lo divino y, en alguna medida, escéptica. Por ejemplo, el influyente escocés David Hume duda y hace dudar de la fiabilidad de todo conocimiento. Duda tanto que se necesitó un Kant para neutralizar tanta duda aunque fuera de un modo parcial. Por su parte en Francia no se duda tan en profundidad. En La Enciclopedia francesa se seculariza abiertamente el pensamiento intuyendo 
que de esa manera se libera al hombre de las cadenas de un dictador divino que en el mejor de los casos nunca existió y, en el peor, está, valga el chascarrillo, "Dios sabe donde", quizá en un lugar en que tiempo ha, posiblemente desde un principio, perdió todo su interés por su creación. Aunque esta actitud deísta en su forma encubra, un tanto implícitamente, un atentado social hacia el orden imperante. Por así expresarlo, la burguesía emergente representada por la nobleza menor quiere el poder de la nobleza mayor, y la mejor estrategia es socavar sus ideales: nadie tiene nada por derecho divino, en el mejor de los casos «hay que repartir" y, en el peor, se debe racionalizar lo que existe o ha existido del modo más mecanicista posible, nace así la Histoire Raisonnée.

Donde tampoco se duda es en Inglaterra, pero esta vez «en el buen sentido de la palabra". Los ingleses siguen siendo romanos aunque sin el Papa. Su rey, asistido por el arzobispo de Canterbury, ya anglicano, asume toda la responsabilidad. Los ingleses, de hecho, dan rienda suelta a una teología natural que hace que para ellos sea evidente la existencia del Dios bíblico, bueno, que cuida de su creación. De modo que aunque el Creador al respecto a menudo nos parezca sospechoso de truculencia, por el dolor y sufrimiento a que somete a sus criaturas, es aceptable en su proceder por la maestría con que está diseñada dicha creación en cada una de esas criaturas para su adaptación al medio en que les ha tocado sobrevivir (más que vivir). Los germanos, por su parte y a pesar de la mesura kantiana, se emborrachan de Dios, como si dijéramos, y se sumergen en un panteísmo un tanto sui generis perfilado un siglo antes por Baruch Spinoza, lo que derivará en la denominada Naturphilosophie, en Hegel y el idealismo germano y posteriormente en el romanticismo.

Viejas ideas sobre un origen del hombre, no mediatizado por la divinidad, aparecen y reaparecen en los contextos justamente indicados ya para quedarse. En definitiva, se temporaliza la Gran Cadena del Ser de los clásicos. El conde de Buffon (Georges Leclerc de Buffon, 1707-88), de la nobleza menor francesa, supone que el planeta tierra, en algún momento un esferoide incandescente, comenzó otrora a enfriarse. Y llegó el instante en que las condiciones para la aparición espontánea de los seres vivos, el hombre incluido, eran idóneas. Y eran idóneas para la aparición de seres perfectos en toda su complejidad (es decir, las condiciones eran óptimas para la ocurrencia de ese evento). Luego con el enfriamiento de la tierra, las condiciones empeoran y los seres vivos «enferman", degeneran. Por ejemplo el caballo degenera en burro, el hombre blanco degenera en seres de otras razas y éstos, a su vez, en monos antropoides y así sucesivamente (por eso veríamos esa enorme variabilidad orgánica en la 
naturaleza, todo fruto de degeneraciones a partir de unos seres perfectos singulares, degeneraciones propiciadas por el deterioro de las condiciones climáticas). Al final de los tiempos ya no habrá nada. La vida del hombre habrá sido algo efímero ${ }^{13}$.

Frente al pesimismo secularizante de Buffon, sobre el origen y destino del hombre, existen otras variaciones, de un pesimismo distinto en sus matices, que luego tendrán plena cabida en nuestros días. Y es que la secularización, desde un principio, le deja al hombre huérfano de las certezas metafísicas que amparan su existencia ${ }^{14}$. Para el newtoniano e ilustrado galo Pierre Moreau de Maupertuis (1698-1759), el origen incierto pero natural de unos seres vivos originales, aparecidos quizá à la Buffon (pero no necesariamente en toda su complejidad), da lugar a toda la variación orgánica existente, porque la reproducción no es un proceso preciso, los organismos se generan de un modo tal que la descendencia no se parece exactamente a los progenitores. Y así, con el tiempo, se van multiplicando las distintas formas, y así con el tiempo aparece el hombre como podría haber aparecido otra cosa. Estrictamente, no hay degeneración ni enfermedad, simplemente, indiferencia orgánica. Y así, con el tiempo, siguiendo la misma argumentación, podrá desaparecer el hombre, del mismo modo casual como ha aparecido ${ }^{15}$.

Benoît de Maillet (1656-1738), por su parte, nos recuerda a Anaximandro. Para este ilustrado francés lo vivo se origina en el mar, y luego por una especie de selección natural, ya casi darwiniana, todo territorio no acuático se va viendo invadido, por formas que aparecen "espontáneamente" (por ejemplo, en el sentido errático de Maupertuis justamente indicado), formas que se ven viables en medios antes inhóspitos, como puedan ser la tierra firme y el aire. Diderot tiene otra versión que recuerda a la de Empédocles. Otra variación novedosa, en este cocktail de ideas evolucionistas, la protagoniza Jean-Baptiste de Lamarck (1744-1829). Para este autor, «el último de los ilustrados", la

13 Un estudio clave sobre este importante autor en el contexto de este escrito es el Buffon: Un philosophe au Jardin du Roi de Jacques Roger (Fayard, Paris, 1989).

14 Claro está que una solución para remediar este estado de cosas del tipo, valga el coloquialismo, de uel que no se consuela es porque no quiere» es acudir a la razón irónica, en los conocidos términos de Richard Rorty, o a la razón cínica de Peter Sloterdijk, apelando al supuesto bienestar de los cínicos griegos que reposaba en una vida sin ideales ni certezas metafísicas.

15 Esta especulación tiene en la biología actual una base firme que compite en sus principios básicos con la teoría de la selección natural y se conoce con el nombre de neutralismo. 
materia sería algo dinámico, y sus estructuras iniciales aumentarían con el tiempo en complejidad debido a dinamismos internos prolijos en su detalle. En este proceso de autogénesis complejizante, tarde o temprano la materia sería lo suficientemente compleja para llamarse viva y llegaría un momento que en ese proceso de autogeneración de la complejidad aparecería el hombre. En dicho instante es como si la materia hubiera alcanzado finalmente un equilibrio en su proceso autogenerador de formas cada vez más complejas. Y ese sería el final de la historia, sin más trascendencia ${ }^{16}$.

El contexto germano de la Naturphilosophie nos ofrece otro mundo, más o menos implícitamente panteísta según los casos. Ahora lo que existirían, al menos de un modo potencial (en el sentido aristotélico del término), serían arquetipos animales y vegetales que se constituirían en estructuras elementales (por ejemplo, la "vértebra" en los animales y la "hoja» en las plantas) que se repiten, se aglutinan integrándose y se modifican convenientemente (así, el cráneo de los vertebrados se compondría de cuatro vértebras modificadas), y así se crearían todas las variaciones posibles que vemos a nuestro alrededor (este proceso se podría observar en el desarrollo embrionario de los organismos). De manera que, en este contexto, como en la concepción estoica, todo se ajusta a leyes naturales insoslayables que formarían parte de una fisiología divina de la que participaríamos todos y todo ${ }^{17}$.

\section{De nuestros dias en adelante}

Pero donde Dios estaba mejor instalado, al parecer surgió su Judas, su traidor, que casi "a la chita callando» no sólo le excluye del mundo sino que, para

16 Un estudio, ya clásico, sobre la variabilidad del pensamiento francés al respecto en el siglo XVIII se debe también al mencionado Jacques ROGER (véase su Les Sciences de la Vie dans la Pensée Française du XVIIIe Siècle, Armand Colin, Paris, 1971, la primera edición es de 1963). Para entender el lugar de privilegio de Lamarck en toda esta odisea especulativa es imprescindible la obra de Richard W. BURKHARDT The Spirit of the System: Lamarck and Evolutionary Biology (Harvard University Press, 1977), a pesar del presentismo del título que no se refleja en absoluto en el texto. Incidentalmente, la especulación lamarckiana también ostenta una base firme en la biología actual que, asimismo, compite en sus principios básicos con la teoría de la selección natural y se conoce con el nombre de direccionalismo (véanse, por ejemplo, mi Los Limites de la Historia Natural: Hacia una nueva biologia del conocimiento, parte I, Akal, Madrid, 2003).

17 Análogamente a lo especificado en la nota anterior, hoy estas ideas también tienen una consideración seria en la biología actual (véase mi Los Limites...). 
muchos, le da el tiro de gracia. Se trata del naturalista inglés Charles Darwin (1809-1882). Y para muchos de esos muchos, con él empiezan "nuestros días». La historia de Darwin como la de sus ideas y derivaciones se conoce muy bien ${ }^{18}$. Las especulaciones de Darwin actualizadas son la ortodoxia actual sobre el origen del hombre y su destino. Darwin le sustituye al Dios de sus ancestros y coetáneos por un proceso de selección natural. Publica en 1859 su El Origen de las Especies por medio de la selección natural o la preservación de las razas que se ven favorecidas en la lucha por la vida y allí ya hacia el final del libro descubre sus cartas abiertamente:

No debemos maravillarnos de que el aguijón de la abeja, al ser utilizado contra un enemigo, ocasione la muerte de la propia abeja; de que se produzca tan gran número de zánganos para un sólo acto, y de que luego los maten sus propias hermanas estériles; ni del asombroso derroche de polen por parte de nuestros abetos; ni del odio instintivo de la abeja reina hacia sus propias hijas fecundas; ni de que los icneumónidos [se está refiriendo a las larvas de ciertas avispas solitarias] se alimenten en el interior del cuerpo de las orugas vivas, ni de otros casos semejantes. Lo realmente maravilloso es, de acuerdo con la teoría de la selección natural, que no se hayan descubierto más casos de falta de absoluta perfección ${ }^{19}$... Según la teoría de que los instintos se han adquirido lentamente por selección natural, no hemos de maravillarnos de que algunos instintos no sean perfectos y estén expuestos a error, ni de que muchos instintos sean causa de sufrimiento para otros animales ${ }^{20}$.

En un mundo no ya abandonado por Dios sino abiertamente sin Dios, no hay diseño ni orden ni concierto. Lo que hay es una apariencia de equilibrio a favor de nadie y en detrimento de todos. Porque, y sobre todo, los seres vivos sufren. Porque, claro está, la selección natural es completamente ajena a su condición doliente. Es más, ya advierte Darwin, casi al principio de su libro más conocido, que no nos engañemos, que los encantos de la naturaleza, como pueda ser el canto de los pájaros, no son más que espejismos que en realidad reflejan la necesidad y el sufrimiento por donde discurre la vida cotidiana:

18 Una historia al respecto especialmente bien tratada por la crítica especializada es la del autor de estas líneas, Teoría Histórica de la Selección Natural (Alhambra, Madrid, 1988).

19 C. DARWIN, El Origen de las Especies (versión española, enmendada, de la sexta edición inglesa, de Aníbal Froufe, Edaf, Madrid, 1981), p. 465.

20 Ibid., p. 467. 
Contemplamos la faz de la naturaleza radiante de alegría, vemos a menudo superabundancia de alimentos; pero no vemos, o lo olvidamos, que los pájaros que cantan ociosos a nuestro alrededor viven en su mayor parte de insectos o semillas y, por tanto, están constantemente destruyendo vida; y olvidamos con qué abundancia son destruidos estos cantores, o sus huevos, o sus polluelos por las bestias de rapiña; y no siempre tenemos presente que, aunque el alimento puede ser en este momento superabundante, no ocurre así en todas las estaciones de cada uno de los años que transcurren ${ }^{21}$.

Incidentalmente, cuando Darwin empezó a especular sobre un origen de las especies ajeno a toda creación divina empezó a tener problemas de salud. La causa de la enfermedad de Darwin, que éste padeciera prácticamente durante toda su vida, ha sido de siempre motivo de perplejidad para los estudiosos debido, sobre todo, al carácter psicosomático de dicha dolencia. El caso es que Darwin tenía pesadillas que reflejaban una sensación de culpabilidad insoportable a causa de sus especulaciones. Y cuando le revela sus ideas al respecto, que guardaba con la mayor discreción, a uno de sus mejores amigos, el director del jardín botánico londinense de Kew, Joseph Dalton Hooker (1817-1911), se lo comunica diciendo que es como "confesar un asesinato». Sí, en cierto modo, valga el melodramatismo, el asesinato era el mayor magnicidio de la historia, el asesinato de Dios. Darwin había abierto la caja de Pandora. Consumarían esa apertura Nietzsche, Marx y luego Freud (los "filósofos" de la sospecha) y allegados (Feuerbach, Moleschott, Büchner, Vogt, y un largo etc.). Pero, en general nadie podía digerir del todo las ideas del naturalista inglés. Ni el mismo Karl Marx pudo hacerlo. Marx aceptaba el origen animal del hombre, pero por su destino se salía de la animalidad y Marx cambió de teórico evolucionista, le eligió al francés Pierre Trémaux, para neutralizar el pesimismo escatológico de Darwin ${ }^{22}$. En cualquier caso, el mismo Darwin deseaba como dar marcha atrás. Se dice, claro está, que sus marchas atrás eran "concesiones a la galería». Juzgue el lector por sí mismo a Darwin en sus contradicciones (que pueden muy bien ser las nuestras):

21 Ibid., p. 102.

22 Véase el extraordinario estudio al respecto que lleva a cabo Giuliano PANCALDI, en la primera parte de la segunda parte, Darwin-Marx, de su Charles Darwin: "storia" ed "economia* della natura (La Nuova Italia, Florencia, 1977). 
No veo ninguna razón válida para que las opiniones expuestas en este libro [El Origen de las Especies] hieran los sentimientos religiosos de nadie. Es suficiente, como demostración de lo pasajeras que son tales impresiones, recordar que el mayor descubrimiento que jamás ha hecho el hombre —o sea, la ley de la atracción de la gravedad - , fue también atacada por Leibniz "como subversiva de la religión natural, $y$, por consiguiente, de la revelada». Un famoso autor y teólogo me ha escrito diciéndome que "poco a poco ha sabido comprender que es una concepción igualmente noble de la Deidad creer que ha creado unas pocas formas primitivas capaces de desarrollarse por sí mismas en otras formas necesarias, como creer que ha necesitado un acto nuevo de creación para llenar los huecos producidos por la acción de sus leyes" ${ }^{23}$... Hay grandeza en esta concepción de que la vida, con sus diferentes facultades, fue originalmente alentada por el Creador en unas cuantas formas o en una sola, y que, mientras este planeta ha ido girando según la constante ley de la gravitación, se han desarrollado y se están desarrollando, a partir de un comienzo tan sencillo, infinidad de formas bellas y maravillosas en extremo ${ }^{24}$.

No nos vamos a detener de un modo directo más en las ideas de Darwin. Pero la secularización del pensamiento se inició hasta tal punto con su obra que, por ejemplo, el padre de la paleontología actual (paleontología interpretada según bases darwinianas), George Gaylord Simpson (1902-84), sugirio que el tiempo se debería contar desde del nacimiento de Darwin y no de Cristo, pues habría sido Darwin el que nos habría sacado del sopor insoportable de la superstición.

En efecto, en la ciencia actual, y fundamentalmente en la biología, el hombre sería una especie de accidente atrapado en un mundo sin sentido. En las palabras más que autorizadas de Jacques Monod (1910-76), uno de los padres de la biología molecular (Premio Nobel de Medicina compartido en 1965 con François Jacob y André Lwoff), tomadas de su El Azar y la Necesidad: Ensayo sobre la filosofia natural de la biología moderna:

... el hombre sabe al fin que está solo en la inmensidad indiferente del Universo de donde ha surgido por azar. Igual que su destino, su deber no está escrito en ninguna parte. Puede escoger entre el reino y las tinieblas ${ }^{25}$.

23 DARWIN (op. cir.), p. 472.

24 Ibid., p. 480.

25 J. MONOD (1970), versión espańola de F. FERrer LerIN, revisada por A. Cortés Tejedor (Orbis, Barcelona, 1986), p. 168. 
Claro está que el reino es la ciencia (la nueva alianza) y las tinieblas (la antigua alianza) vienen a ser la teología y la metafísica tradicional (Monod cita a Marx, al filósofo Henri Bergson, al teólogo y paleontólogo jesuita Pierre Teilhard de Chardin, entre todo un pot-pourri de presuntos implicados). Lo que no cuadra del todo es que ante la devastadora desolación de un mundo absurdo y sin sentido haya esperanza de adquisición de sentido. Pero, para Darwin se adquiere sentido por selección natural, aunque sea por casualidad, y para Monod se adquiere sentido por medio de la inteligencia, también aparecida por casualidad y, eso sí, siempre consolidada por selección natural ${ }^{26}$.

\section{Reacción ante la ciencia}

Pero existe, especialmente en lo que llamamos Occidente, un enfrentamiento frontal a la visión de la ciencia. Es verdad que la mayor parte de los científicos aceptan vivir en un mundo sin sentido, ni dirección. Simplemente, es como si adoptaran el principio aristotélico de que el máximo placer para el hombre es la contemplación de la verdad, esté ésta respaldada por una divinidad o simplemente por "nada". Pero vivimos en un mundo polarizado, en un mundo que el científico y novelista inglés $C$. P. Snow, denominó hace medio siglo el mundo de las dos culturas: la cultura científica y la cultura humanista. Independientemente de que un científico pueda ser un humanista, o al revés, los humanistas pensarían que mediante el arte en sus diversas manifestaciones (literatura, pintura, música) accedemos a una realidad más allá de las limitaciones de la realidad aceptable por la ciencia que, por esa razón, no sería describible tecnocientíficamente más allá de una perspectiva meramente instrumental. Los científicos a machamartillo, por su parte, manifestarían que de ilusión también se vive, y que la única realidad es la que refleja la ciencia, es decir, la cruda realidad cotidiana, la realidad sin atributos inefables.

Últimamente, el problema de las dos culturas se ha agravado considerablemente y se ha convertido en lo que se llama "la guerra de las ciencias". El detonante fue el artículo-trampa que un físico, Alan Sokal, envió a una revista americana de humanidades, Social Text y que ésta publicó en 1996. Artículo-tram-

26 Esta idea está muy extendida (véase, por ejemplo, el texto reciente de Donald CAMERON, The Purpose of Life (Woodhill Publishing, Bristol, 2001). 
pa porque se escribió como una broma con la pretensión de que los humanistas "de profesión" se lo tomaran en serio y de esta manera se vieran desenmascarados en su incompetencia intelectual. Porque para Sokal, como para la mayor parte de sus colegas (físicos y biólogos principalmente), sólo habría una cultura que sería la científica, todo lo demás serían "buenas intenciones" en el mejor de los casos y charlatanería en el peor ${ }^{27}$. Pero, claro está, los humanistas consideran que lo que rebela incompetencia cultural es la trampa y el fraude, de tal manera que la base para una controversia interminable no es que esté servida sino que viene de antiguo.

Después de todo, la reacción romántica a la ilustración no es más que un ejemplo de la misma tesitura. Y antes, en el Renacimiento, como especifica el conocido filósofo finlandés, Georg von Wright, en el primer capítulo de su espléndido libro, Comprensión y Explicación (sobre la base diltheyana de que el científico meramente explica, mientras que el humanista comprende), estaba presente la controversia entre los aristotélicos (que creían en la causa final de cualquier explicación, es decir, en el sentido de las cosas) y los galileanos que se centraban únicamente en la causa eficiente ${ }^{28}$.

La ciencia, desde sí misma, nos introduce en un mundo absurdo, pero que sería disfrutable en la tarea de descubrirlo. Las humanidades por su parte, nos invitan a entrar en un mundo supuestamente lleno de sentido en que o bien, en un extremo, los creadores somos nosotros o bien, en otro extremo, el autén-

27 Sokal con otro físico, el belga Jean Bricmont, han manifestado todas estas inquietudes en su Impostures Intelectuelles (Odile Jacob, París, 1997), obra que apareció en Inglés al año siguiente y en castellano en 1999. Destaca, entre las numerosas réplicas que Sokal y compañía han recibido, la de Quintín RACIONERO, "La resistible ascensión de Alan Sokal: reflexiones en torno a la responsabilidad comunicativa, el relativismo epistemológico y la postmodernidad" en Endoxa: Series Filosbficas, n. ${ }^{\circ} 12,2000$, pp. 423-83.

28 En realidad, se trata de la tensión siempre latente entre los "saberes" nuevos y los tradicionales. Por ejemplo, dentro del humanismo fue notable en los años 60, del siglo pasado, en Francia, la controversia entre el "moderno" Roland Barthes y el "tradicional" Raymond Picard debido al escrito Sur Racine del primero que el segundo contestó con su Nouvelle Critique ou Nouvelle Imposture. Hoy día el movimiento vanguardista conocido de un tiempo a esta parte como postestructuralismo, que tanto critican los sokalianos por ejemplo, se califica por los marxistas de última hornada, como pueda ser el conocido Fredric Jameson, como movimiento de derechas, derechas que, a su vez, reivindican para sí autores como Alasdair MacIntyre, e incluso el recientemente fallecido Hans-Georg Gadamer, que nada tienen que ver con el postestructuralismo. Por supuesto que, en cierto sentido "todos están a la última», de manera que no está a menudo del todo claro quien está por delante y quien se queda rezagado. 
tico Creador nos "ignora" del todo aunque indirectamente nos indique un camino a seguir. De manera que el mundo absurdo que, especialmente desde Darwin, ofrecen los científicos, con ánimo de expresar una superioridad suministrada por la supuesta racionalidad de la ciencia, tiene su contrapartida en ese otro mundo oscuro donde racionalidad y superstición se funden en un nexo que por dificultoso que sea intelectualmente no es menos real, y que le puede llegar a dar a la concepción absurda de la existencia una versión teológica una tanto tragicómica. Como aventura el ex-seminarista jesuíta, George A. Blair, Catedrático de Filosofía en el Colegio Tomás Moro de Kentucky, en Estados Unidos, en un documento cuanto menos sorprendente, en la perspectiva que se indica, cuanto más porque está supuestamente encuadrado dentro de la ortodoxia cristiana:

Un cristiano que intenta remediar los males de este mundo es un cristiano que ha sucumbido a la mentalidad técnica ${ }^{29}$... Desde el punto de vista de Dios, el mal no existe. Dios ve las cosas como son y no como "deberían" ser... De modo que Dios no puede ver las cosas en su maldad sino en su ser... Dios es completamente feliz a pesar de todas las miserias de este mundo -incluso con la miseria eterna de las almas que se consumen en el averno-. Entonces, ¿qué se espera que haga el cristiano en tanto que cristiano? Nada especial, sólo ser feliz. ¿Debe implicarse en las tareas de su comunidad? No necesariamente. ¿¿Debe tratar de remediar la pobreza de sus semejantes? No necesariamente. El cristiano en tanto que cristiano lo respeta todo infinitamente, y si tiene esta actitud divina, se ve totalmente libre de obligaciones. No tiene que hacer nada, hace lo que le viene en gana. La vida para él no es algo serio, es un juego - porque el universo para él no es algo que haya que tomarse en serio-. En el orden eterno de las cosas, nada es importante, porque nada "debería ser" de una determinada manera. Dios es infinitamente feliz independientemente de lo que el mundo haga de sí mismo, y así nada puede alterar la felicidad del cristiano... En un sentido profundo se puede y se debe decir que a Dios no le importa nada lo que pase en el mundo ${ }^{30}$.

Y por si esto fuera poco, prosigue Blair:

29 P. 47 del artículo "Faith outside technique" en Theology and Technology - Essays in Christian analysis and Exegesis, edición de Carl Mitcham y Jim Grote, University Pcress of America, Lanham, 1984).

30 Ibid. p. 48. 
¿Pero no contradice todo esto la esencia del cristianismo? ¿Si a Dios no le importa lo que hagamos? ¿Por qué murió por nosotros? ¿Por qué nos redimió en la cruz? Preguntar el "por qué» de un ser que es absolutamente completo es preguntar algo que es fundamentalmente absurdo. Lo hizo, ciertamente no porque le importunaran nuestros pecados, ciertamente tampoco para que seamos mucho más felices, jsino - siempre que nos tomemos la intencionalidad de Dios en serio- porque podía hacerlo! Y así los seres humanos tienen una oportunidad de eludir las consecuencias de sus pecados, siempre que quieran aprovechar la ocasión. Pero si no lo hacen, Dios es perfectamente feliz. No le importa en absoluto si esos seres humanos van al infierno $^{31}$.

Es más,

El cristianismo nos muestra como nos ama Dios. Nos ama tanto que no le da importancia a ser Dios, sino que se convierte en un esclavo, en un servidor de la muerte, y muerte de cruz (Filipenses 2:5-8). Su propia realidad no le importa. Y esta es la actitud que se espera que nosotros adoptemos. No tenemos que dar ninguna importancia a nuestra propia realidad. La muerte de Jesús no muestra la importancia que tenemos ante los ojos de Dios, justamente lo contrario. Lo que muestra -en un sentido no sólo filosófico, sino bíblico- es la escasa importancia que deberíamos darnos ${ }^{32}$.

En definitiva, según Blair, la explicación está clara:

Esto es, Dios creó el mundo para que sea lo que es, no necesariamente para que tuviera un sentido... Para Dios no significan nada las decisiones humanas con respecto a si el mundo va por "buen" o por "mal" camino... Pero entonces, si nada importa, ¿por qué molestarse en tratar de conseguir algo? Y la respuesta forma parte de la respuesta divina sobre la razón que le ha impulsado a Dios a crear. ¿Y por qué no? Un acto no tiene por qué tener un sentido más allá de su propia consecución. Existencia es inteligibilidad. Y lo que es sumamente interesante es que la definición de "pasarlo bien" es simplemente hacer algo por el gusto de hacerlo, sin más trascendencia. De modo que si adoptamos la actitud divina hacia nuestros actos, convenciéndonos de que nada importa, entonces nuestra vida adquiere sentido, no por-

31 Ibid.

32 Ibid. p. 49. 
que haya algo más allá, sino por nuestra vida así en sí misma —entonces toda nuestra vida será buena- ${ }^{33}$.

\section{En resumen}

... de hecho nada tiene importancia, ninguno de nosotros la tiene, y como esto es así, tarde o temprano tendremos que enfrentarnos a esa realidad, a la realidad. Tendremos que afrontar el hecho de que los objetivos por los que luchamos no tienen absolutamente ninguna importancia en el marco de la eternidad. Y para aquéllos para quienes lo que les importa es que ni ellos mismos ni sus preocupaciones merecen la pena, así objetivamente, esto es el infierno. Para aquéllos, empero, para los que nada de esto tiene relevancia, esto es el cielo ${ }^{34}$.

La aparente heterodoxia de las ideas de Blair se entronca bien no sólo con el misticismo clásico de un Plotino, dentro de la tradición occidental, sino con el misticismo de un meister Eckhardt, de un Angelus Silesius, de Juan de la Cruz, de Miguel de Molinos, y de tantos otros. Para los místicos, después de la "noche oscura" se entra en "la nada", pero no en una nada nihilista en el sentido coloquial del término, sino en la divinidad despojada de toda experiencia humana terrenal, contingente, despojada en fin de todo lo experimentado y conocido en la vida normal. Y, claro, cuando uno se despoja de todo no queda "nada". Por cierto, ésta sería una nada análoga a la heideggerina de ¿Qué es metafísica?, lección magistral con la que Martin Heidegger inaugura su cátedra de filosofía en Friburgo en $1929^{35}$. Y siguiendo con la analogía, esa "nada" entroncaría con "lo real» lacaniano (como a la sazón dice Richard Boothby, "una abstracción pertinente es que la noción de lo real, como la de la nada de Heidegger, sólo genera paradoja y aporía; pero, del mismo modo que esa nada, la presencia de lo real se integra en la experiencia humana fundamental de la ansiedad» ${ }^{36}$ )

33 Ibid., p. 50.

34 Ibid., pp. 50-1.

35 Incidentalmente, Hermann HESSE publica en 1922 su Siddahartha: Eine indische Dichtung donde se plasma una versión "oriental" del texto de Blair (véase el último capítulo titulado "Govinda").

36 P. 148 de su Freud as Philosopher: Metapsychology after Lacan (Routledge, Nueva York, 2001). 


\section{El marco de lo real (La cara oculta de la tradición)}

\section{«Interludio» (entre un pasado brumoso y un presente a la deriva)}

Se constata entonces que para dilucidar el origen de los seres humanos, todas las culturas precedentes a la actual dentro de la línea de Occidente, en mayor o menor medida, han contemplado su aparición de una manera inefable. Ahora, esta operación está concluyendo en nuestra cultura. En efecto, como se ha estado repasando, la cultura occidental está suprimiendo la inefabilidad desde la ciencia. Desde esta perspectiva, la cultura occidental lo está convirtiendo todo en algo inerte. La vida se está acabando. Lo vivo está muriéndose ${ }^{37}$.

Antes de que el hombre occidental tomara forma ${ }^{38}$ todo su anterior estado era estático (su estructura social era "fría", al decir de Lévi-Strauss). La vida permanecía inmutable porque todo estaba vivo. Vivo y jerarquizado. Había niveles de responsabilidad vital. En un nivel solían estar los creadores del mundo, los dioses o un Dios todopoderoso o un Demiurgo Creador a partir de algo preexistente. En otro nivel estaban los animales y los extranjeros y, a menudo, las mujeres, que serían humanos inferiores y como tales utilizables como esclavos, siervos o sirvientes. De manera que el hombre genuino era como un puente entre una realidad que se corrompe y pasa y otra que es eterna y cambia y se renueva y, en el fondo, nunca desaparece. Desde esta visión del mundo, la gran pregunta occidental de "por qué hay algo en vez de nada", la pregunta del Ser que comparten todos los seres, es algo que no es que no

37 De hecho, podemos decir que "la muerte oficial de la vida" se certifica públicamente un 28 de febrero de 1953 cuando el físico Francis Crick (Premio Nobel de Medicina con James Watson y Maurice Wilkins en 1962) entra al caer la tarde en el pub The Eagle de Cambridge y le anuncia a sus "amigos" algo así como: sefiores he descubierto el secreto de la vida (ese mismo día había dilucidado con el jovencísimo biólogo James Watson, posteriormente padre espiritual del proyecto genoma, la estructura del $A D N)$.

38 Es más, esta "forma" implicaría, desde la ciencia positiva, la consumación de la antropogénesis, en el sentido de que el hombre "civilizado", como hombre "ilustrado", sería el hombre "verdadero"; el otro hombre sería todavía un antecesor algo «menos" humano por ser todavfa presa del pensamiento supersticioso. Este aparente pero apenas discutible disparate es, a todas luces, moneda de curso legal incluso desde la antropologia (recuérdese que, por ejemplo, Lévi-Strauss propone que las sociedades primitivas "amplían" el mundo combinando y recombinando elementos ya existentes "a manera de bricolage", mientras que con la ciencia occidental se trascendería ese estado primigenio conceptualizando. El mensaje es que no trasciende quien quiere, sino quien puede; para más detalles de esta espinosa cuestión se podrá consultar mi "Hacia una hermenéutica..."). 
tenga sentido, sino que su planteamiento sería de suyo perverso (la cuestión sería pertinente en una sociedad "caliente", de nuevo en la terminología de Lévi-Strauss ${ }^{39}$ ).

Pero como se acaba de afirmar, normalmente las culturas añejas que han sido, y alguna otra que apenas permanece, han sido estáticas. Estáticas en el sentido de alimentar una tradición única que se ha ido siempre consolidando en lo que se ha asumido como su esencia. Los seres humanos, en su generalidad, han soportado mal desviaciones a partir de una norma de vida establecida desde tiempos inmemoriales (trivialmente, mientras más se consolida una forma de vida más cuesta, llegado el caso, romper su inercia). El hombre-hombre de, en cualquier caso, reciente aparición (¿̨hace 100.000 años?), paradójicamente, se ha sentido en casa en su medio recién adquirido (allí donde se fraguara su autoconciencia), con los otros y consigo mismo. $Y$ cuando el medio ha variado, siempre para mal, las poblaciones humanas han preferido emigrar, o simplemente extinguirse, o permanecer en ese medio primigenio (que no prístino) que se iba yendo pero secundado por una esperanza de que la norma volviera ${ }^{40}$. Ha habido pasividad con lo que se ha creído inevitable. Porque si no se puede vivir como se ha vivido «siempre", de entrada se pierde el norte, todo se desmorona ${ }^{41}$.

Los dioses, el medio, los otros, los esclavos, prácticamente todos tenían un papel asumido en ese mundo primigenio. Extrapolando a ese mundo ancestral,

39 Incidentalmente, se ve claramente que no en vano dice HEIDEGGER en su La Epoca de la Imagen del Mundo (1938): "En el advenimiento de la antropología Descartes celebra su mayor triunfo. Con la antropología se inaugura el paso de la metafísica hacia el mero cese y eliminación de toda filosofíam.

40 De hecho, el gran cambio del hombre primitivo fue el paso de cazador-recolector a agricultor, transición, en su momento, muy para mal (véase, Colin TUDGE, 2000, Neandertals, Bandits and Farmers: How agriculture really began, Weidenfeld \& Nicholson, New Haven, 1998).

41 Naturalmente, este contraste interpretativo que se está estableciendo entre sociedad establecida (tradicional) y lo que viene después tendría su inicio oficial en la reacción Sturm und Drang del romanticismo alemán que de alguna manera adquiere carta de naturaleza ya uen nuestro tiempo" en la obra de Ferdinand Tönnies Gemeinschaft und Gesellschaft (1887), contraste que en la obra coetánea de Émile DuRKheIM De la Division du Travail Social (1893) tiene una evaluación opuesta a la de Tönnies, lo que, incidentalmente, ejemplifica de un modo sobresaliente el contraste análogo entre el humanismo "de fondo" alemán y el galo que tanta relevancia tendría medio siglo después en la Carta sobre el Humanismo (1947) con la que Heidegger impugna el humanismo existencialista sartreano. 
a partir de los numerosos relatos antropológicos existentes sobre los pueblos llamados primitivos ${ }^{42}$, no existía de una manera explícita ni la felicidad ni la infelicidad. Simplemente se vivía, mal que bien (aunque desde nuestra perspectiva pareciera que era mucho más mal que bien). Como digo, todo estaba vivo y todo influía en todo (animismo/finalismo generalizado). Toda acción por parte de cualquier individuo o estaba prohibida o era obligatoria ${ }^{43}$. La libertad de acción estaba enormemente limitada. La libertad a lo occidental tenía poco sentido. Cualquier cambio de papeles era una transgresión que rompía el equilibrio establecido. En el mejor de los casos, la transgresión se pagaba con compensaciones desincentivadoras en sufrimiento ${ }^{44}$. En el peor de los casos, se llegaba al fin rápida o lentamente para que luego todo volviera a su lugar natural (a su sitio). La autoconciencia estaba donde tenía que estar, valía para sobrevivir y no para amargarle la existencia a su portador. El destino se hacía cargo de todo. El dolor y el placer cotidianos concurrían, no se buscaban. La supuesta búsqueda engendraba culpabilidad. Y la culpabilidad, a su vez, originaba miseria, descentraba e invitaba a la propia destrucción y, por contaminación, hacia lo demás.

El hombre, el medio, los otros, estaban como prisioneros en una reserva fuera de la cual amenazaba lo desconocido. La tierra, el cielo, los hombres, los dioses estaban atrapados en su propio paraíso, o en su propio infierno si se quiere. No había ni tiempo ni lugar para heterodoxias mayores, ni siquiera para distracciones que no estuvieran programadas por una tradición que lo era todo. La libertad no liberaba sino que ahogaba en la perplejidad de "afinidades electivas" nunca realmente deseadas. La verdad y la realidad se llevaban dentro. Ocurrían en un círculo sin salida. De hecho, cualquier posible salida era una trampa. La verdad de la esencia era la esencia de la verdad (tomando otro título de Heidegger aunque dándole una connotación directamente antropológica).

¿Había culminado la antropogénesis? ¿Había coronado la cima el hombre en su aparición? ¿Había bajado alguna vez de esa cima? Pero apareció

42 Tomo como modelo de partida, por un lado, la divulgación, en clave marxista, del gran antropólogo recientemente fallecido, Marvin HARRIS, Our Kind: Who we are, where we came from, where we are going (Harper \& Row, Nueva York, 1989) y, por otro lado, el artículo de Aron GURWITSCH "The last work of Edmund Husserl" en Aron Gurwitsch's Studies in Phenomenology and Psychology (Northwestern University Press, Evanston, 1966), pp. 399-447.

43 En una sociedad animista, la "intencionalidad" está repartida por doquier.

44 Una contextualización análoga se encuentra en la obra publicada en 1948 por Georges Batallle Teoria de la Religión (tr. De Fernando Sabater para Taurus, Madrid, 1981). 
Occidente en una plenitud inusitada. Todo ese mundo estático se vino abajo. Surgió una dinámica que hizo de la desviación virtud. ¿Comenzó así la antropogénesis real frente a una posible virtualidad anterior? ¿Qué propició el paso de la sociedad fría primigenia a la caliente de un «tiempo" a esta parte? ${ }^{45} \mathrm{La}$ caracterización es desde luego la de una tecnología desatada. Pero lo que interesa constatar es si ese "nuevo" hombre se acopla a su "nuevo" medio camino de la tecnificación del modo tan ajustado como lo hizo su supuesto antecesor al suyo; porque esta "novedad" humana se sigue forjando ahora, deshaciendo a su precursor. Pero su precursor está tan cerca de su sucesor, hay una identidad tan cercana que quizá en ese deshacer aborte la antropogénesis y lo que lleva aparejado, al menos la conciencia de la verdad y de la realidad ${ }^{46}$.

La desviación decisiva al respecto oficialmente se decanta en lo que denominamos Renacimiento. Allí renace el pasado mejor. Se impone la vuelta a unos orígenes cuasi-míticos donde nada realmente fue lo que parece que fue, aunque mejor hubiera sido que hubiera sido, valga el juego de palabras. En efecto, se comienza a construir idealmente el pasado empezando por contratos sociales imaginarios y se hace así ficción de lo real. Se reconstruye la historia separando una supuesta racionalidad de su lado oscuro. Al final lo reconstruido como lo que merece la pena es lo creíble ${ }^{47}$. ¿Es mejor lo que «había» o lo que hay? ¿Será todavía mejor lo que habrá? ¿Hacia donde vamos? ¿Qué hacemos?

\section{Sobre la noción de Occidente}

Lo primero que ha hecho el hombre obligado por circunstancias más bien oscuras ${ }^{48}$ a pensar en tratar de alcanzar algo más que su propia supervivencia

45 Recuérdese que aunque el hombre-hombre apareciera hace unos 100.000 años no empieza a dar señales de vida intelectualmente "caliente" hasta hace unos 30.000 ańos.

46 En esta tesitura es interesante remitirse a la obra reciente de James HEARTFIELD, The Death of the Subject Explained (Hallam University Press, Sheffield, 2002).

47 Este es exactamente el proceso que relata Steve Woolgar para el quehacer científico en su Ciencia: Abriendo la caja negra (Anthropos, Barcelona, 1991, en tr. del inglés de Eduardo Aibar); en otras palabras, la «realidad» histórica se crearía del mismo modo que la «realidad» natural. En definitiva, Lo Real no tiene por qué tener "zonas francas".

48 Siguiendo a Francis Bacon (1561-1626), un detonante básico fue el tripartito de inventos orientales, la brújula, la imprenta y, posiblemente, sobre todo, la pólvora que destruyendo fortificaciones contribuye a acabar con uno de los pilares del feudalismo. Estas circunstancias 
"aquí y ahora», es salir de ese "aquí y ahora», adentrarse en la incertidumbre de situaciones ignotas. La osadía de sobrevivir en un medio ajeno al de siempre no puede crear de improviso nuevas tradiciones, nuevos equilibrios. No se puede improvisar una situación inmemorial. Procede una huida hacia adelante. Aparece así una temporalidad historiada, un pasado desde el que nos vaciamos hacia el futuro, porque el presente fuerza la terrible elección entre una imposible vuelta atrás y un espeluznante adentramiento hacia lo absurdo de un medio sin tradición, donde yo estoy perdido con los otros, donde me miro existiendo por existir, sin relación cohesionada con lo que me rodea. Porque la tradición aunque ahogue y atenace, protege, lo ata todo con referencias asentadas, es decir, con significantes consolidados (independientemente de que haya significados genuinos). En la occidentalidad, siguiendo ahora plenamente a Heidegger, estoy, nunca mejor dicho, arrojado en el presente ${ }^{49}$.

Personalizando más en profundidad, la única manera de crear un vínculo con lo que fui, históricamente se entiende, con lo que no pude seguir siendo, con lo que le daba contenido a mi existencia, es hacer de la temporalidad "desocultada» algo estático, que es como hacer de la huida una forma de vida. Una directriz es dejar, por ejemplo, la vida nómada de cazador-recolector de alimentos por otra de cazador-recolector de sentido. Porque la necesidad histórica me obliga a establecerme en un entorno foráneo por lo irreconocible, por lo domesticado, por lo forzado a comportarse como "yo quiero" ${ }^{50}$. Me procuro así una seguridad artificial, y por ello, por así decirlo, naturalmente inauténtica. En definiva, yo también me domestico. Lo importante se ha redu-

unidas al crecimiento de las ciudades, o sea de la burguesía, junto con la decadencia del papado y el surgimiento de las monarquías absolutas sobre pedestales de barro prepararían el terreno para el advenimiento de la Revolución Industrial.

49 De hecho, el mensaje de este párrafo es perfectamente acorde con el pensamiento esencial de MacIntyre, expresado por ejemplo en su Tras la Virtud, aunque la justificación bioantropológica nos es propia (de hecho toda la obra de Gadamer, especialmente ejemplificada en su obra maestra, Verdad y Método, está en esta línea como se puede cotejar en el espléndido escrito de Quintín Racionero, "Heidegger urbanizado: Notas para una crítica de la hermenéutica», Revista de Filosofia, 5, 1991, pp. 65-131).

50 Igualmente, el eco de estos asertos debe recordar la línea emprendida en La Pensée Sauvage por Lévi-Strauss, aunque el matiz en nuestro texto sea sobre el paso hacia la mente domesticada, porque el pensador galo no elabora sobre lo que sucede en esa "tierra de paso" que es una «tierra de nadie». En un sentido paralelo se puede asimismo hacer referencia al etólogo primigenio Desmond MORRIS en su obra, ya clásica, El Zoo Humano (tr. De Adolfo Martín, Orbis, Barcelona, 1986). 
cido a seguir comiendo, durmiendo, a seguir el juego de la reproducción, a forzar la producción domesticada para realizar esas funciones. Porque ya todo es extraño. Con la desaparición del sentido, se desvanecen ya todas las certezas y, lo que es quizá peor, también los espejismos ${ }^{51}$.

Antes en ese paraíso-infierno perdido no cabía pensar ¿y qué hago ahora? ¿y por qué hago esto ahora? ¿y por qué pierdo mi plenitud? ¿y por qué muero? ¿y por qué enfermo? Antes ocurría todo esto, pero no se percibía como referencia directa a la propia condición porque formaba parte de las cosas, de cómo es todo, del trasfondo. Ahora, en cambio, me consuelo y pienso, "me he liberado, antes era como un animal, sentía sin sentirmen. Ahora puedo eliminar lo que duele, favorecer lo que es agradable, aunque sea a fuerza de "forzar» por medio de la ciencia, de la tecnología. Pienso que la mejor manera de destruir ese pasado pseudo-animal es devaluarlo. Explicarlo de tal manera que me vea ahora mejor de lo que estaba. Incluso puedo reinventar, con las sutilezas de la erudición actual, esa edad de oro que no recuerdo pero que creo vislumbrar, y lo que sí apenas rememoro es la caída, la salida de un paraíso que mi memoria no alcanza a adumbrar porque en el fondo no creo que las cosas fueran ni siquiera remotamente mejores de lo que se me antojan que son ahora.

\section{A vueltas con Babilonia, Egipto, Grecia, Roma, el sacro imperio y los ingleses}

Sí, vuelvo, en el mal sentido de la expresión, a la situación ancestral de comer, dormir, reproducirme, trabajar para seguir comiendo, durmiendo, reproduciéndome ${ }^{52}$. Si estoy "abajo» lamento mi suerte porque pienso que hay algo más que me pierdo y que hacen los de "arriba". Si estoy "arriba» tengo que llenar mi tiempo con sucedáneos de lo que hacen los de «abajo». Invento la felicidad ${ }^{53}$. Pienso

51 De nuevo, en esta contextualización bioantropológica tanto la ironía rortyana como el cinismo de Sloterdijk están de más.

52 Vease en este sentido la muy ilustrativa obra de Susan ALLPORT The Primal Feast: Food, sex, foraging and love (Harmony, Nueva York, 2000).

${ }_{53}$ Ya se sabe la boutade que, según Nietsche y Marx, la felicidad era algo que deseaban los ingleses; en el contexto del presente escrito, empero, la felicidad, siendo algo consustancial al "nuevo orden" tecnocinetífico, no debe sorprender que los ingleses fueran pioneros en ese deseo de un placer terreno tan inefable como concupiscente. 
que soy más feliz ${ }^{54}$. Pero soy consciente de que tengo que proteger mi situación. Soy consciente de que estoy constantemente amenazado por la falta de sentido, de dirección. Antes era igual, como con los ciervos, o las aves, o cualquier animal, cada uno tiene su sitio, más o menos apetecible, pero no hay cuestión ni de justicia ni de igualdad de oportunidades en un sentido actual. Pero antes, mi autoconciencia, mi conciencia toda, estaba como en consonancia con su medio, protegida de sus propias dudas. Ahora en un mundo que no "conozco", donde no me identifico porque mis nuevos referentes no me anclan, necesito la precisión de nuevos "utensilios", que no son tales sino que son algo así como utensilios de utensilios de manera que los otros, yo mismo, somos utensilios los unos de otros. Necesito matemáticas, medicina, ingeniería, legislación explícita, todo al por mayor, esto es, tecnociencia en un sentido amplio. En un mundo que ya no es mío, necesito sobre todo comprender (filosofía) y, tímidamente, esperar (teología), eso sí muy tímidamente y casi de soslayo, porque la teología recuerda mi huida, mi "caída" hacia arriba (ingravidez), mi imposible retorno hacia la inconsciencia de una existencia posiblemente tan absurda como se me antoja la presente, pero de la que no era consciente. Necesito, en todo caso, la teología sardónica de Blair ${ }^{55}$.

Antes, mi existencia no tenía por qué tener sentido, ahora el sentido es una necesidad imperiosa. Sí, necesito, sobre todo si estoy "arriba", filosofía o autoengañarme sobre que, desesperadamente, nada ha cambiado y sigo envuelto en esa eterna metáfora de los hombres, los dioses, el cielo y la tierra, de que la temporalidad como limitación insoslayable no va conmigo ${ }^{56}$.

Veo mi historia, como si fuera mi biografía. Me veo en los babilonios, asentado, en un mundo ya incipientemente masificado donde la especialización se abre paso. Ya no poseo el conocimiento, sino que es al revés, el conocimiento determina mi lugar en el mundo. Empiezo a "ser parte de». Con los griegos llega otro jinete pseudoapocalítico, el ocio. Todo está resuelto. Mis especialistas me atienden. Yo me escapo del especialismo, pero no para volver atrás, sino

54 Como bien dice Terry EAGLETON en su The Illusions of Postmodernism (Blacwell, Oxford, 1996), «in a move which much of antiquity would have found astonishing, then, the good life has now become a private affair, while the business of matching it remains public" (p. 77).

55 Véase su larga cita en la primera parte de este escrito.

56 De hecho, desde la etología más actual el autoengaño sería una de las adaptaciones biológicas más consolidadas, véase mi La Marsopa de Heidegger: El lugar de la ciencia en la cultura actual (Dykinson, Madrid, 2003), capítulo IV. 
para no hacer nada. No me queda más que filosofar. ¿Qué es el bien? ¿Qué es la belleza? ¿Qué es la justicia? ¿Qué es la amistad? Claro, en este plan, en algún momento concluyo que «sólo sé que no se nada». Pero me tengo que distraer. Me transformo, por ejemplo, en Aristóteles. Catalogo el mundo. Diseño un sistema de categorías en que todo entra: materia, forma, esencialidad, accidentalidad, teleología.

Pero me hago romano y voy a lo práctico. A dominar el mundo conocido. A construir un derecho, comunicaciones, ciudades, un nuevo mundo de todos, para todos. ¿Cuál es el límite? Viene algo así como un respiro. El mundo se hunde. Viene otro mundo, llega la infrahumanidad, los bárbaros, todo queda arrasado. Pero de las cenizas emerge tenuemente un nuevo equilibrio: el papado (la corte de San Dámaso, Inocencio, León, Gregorio Magno, Calixto y Bonifacio). El único refugio parece ser otro mundo, una realidad paralela, ¿qué digo? Una realidad genuina. Vuelven así los greco-romanos pero rebozados de fe. De fe en algo nuevo que quiero desear y que no sé lo que es. La fe que hipoteca todos mis anhelos frustrados, toda la añoranza de una tradición perdida y al mismo tiempo no deseada. Empiezo a vivir una doble vida: el poder temporal y el otro poder. Pasan los siglos. El sacro imperio es a la vez romano (prepotente, esperanzado), griego (ocioso, obsesivo) y babilónico (técnico, especialista).

Pero en esa huida hacia delante, cada vez más acelerada, hay que buscar otras fórmulas porque las anteriores van perdiendo ímpetu, impulso tranquilizador. Las traen los ingleses, nativos, vecinos (escoceses e irlandeses anglicanos) y exportados (americanos y otros). Los ingleses en este sentido amplio conservan las fórmulas anteriores. Creen en el especialismo (Adam Smith), tienen en su ocio esa obsesión por la verdad a la que dan una dimensión teológico-naturalista (John Ray, Robert Boyle, John Bunyan, Richard Baxter, Isaac Newton, Joseph Priestly, William Paley, los tratados "Bridgewater», los «Essays and Reviews»), además de rienda suelta a su prepotencia tecnológica que desemboca y se desboca en la Revolución Industrial.

El desarrollo de esa dimensión teológico-naturalista es la que marcará la diferencia que dura hasta nuestros días. Diferencia que también está dando ya muestras de agotamiento como estrategia de una razón colectiva para seguir viviendo, para seguir en la brecha. Naturalismo que en Darwin ya empezara a estar desprovisto de toda teología concertante. 


\section{La idea naturalista y el final de la humanidad}

La física hasta que se la identificó como física era filosofía natural. La biología hasta que se la identificó como biología era historia natural. Todo esto ocurriría durante el siglo XIX. Y a la filosofía moral hasta que se la identificara como filosofía moral seguía siendo ética. Posteriormente, en el mundo ya más cercano, la ética se empezó a englobar por los anglosajones en la etología y luego por los angloamericanos en la sociobiología y actualmente en la psicología evolucionista ${ }^{57}$. Estas últimas identificaciones-integraciones comenzaron con Darwin, se exacerbaron con William Hamilton, George C.. Williams, Robert Trivers, Edward O. Wilson, Richard Dawkins ${ }^{58}$ y otros, en el siglo que acaba de concluir, y sigue consolidándose en lo que ya casi es un juego en una especie de partida que posiblemente se está acabando. Porque la ciencia y la tecnología viven de sorpresas (abducciones), si se acaban éstas se acaba el reclamo ¿Y entonces qué? ¿Surgirá otra fórmula "salvadora"? ¿ $\mathrm{O}$ por fin el hombre se parará a "pensar" en el sentido heideggeriano del término u otro afín?

Porque cuando Heidegger dice que hay que pensar y que la ciencia no piensa se refiere muy especificamente a esa manera de ser occidental, esa manera científico-técnica que proyecta la existencia en un sentido limitado a esa dirección científico-técnica donde todo existe como si todo fuera algo inerte, almacenable para su uso -incluidos los seres humanos- (el ejemplo más crudo de Heidegger es el almacenaje de judíos durante la segunda guerra mundial que llevó a su utilización como producto de consumo de la manera que todos sabemos).

La idea heideggeriana es paralela a la que expresa Miguel de Unamuno en su "que inventen ellos" porque "él tiene cosas más importantes en que pensar». Pensar en su propia muerte, en su propia finitud que es lo que Heidegger identifica con una existencia auténtica. Razonablemente, con la pérdida del sentido de la existencia, se pierde el sentido de la autenticidad. Si nos tomamos a Darwin en serio ${ }^{59}$, sólo hay accidentalidad y ahí no cabe nada «autén-

57 Es verdad que hay una oposición destacada personificada, por ejemplo, en los biólogos de Harvard, Stephen Jay Gould, recientemente fallecido, y Richard Lewontin.

58 Ver mi Los Limites..., 2. ${ }^{2}$ parte.

59 Un paso firme pero insuficiente en este sentido fue el que dio Michael RUSE con su Tomándose a Darwin en serio: Implicaciones filosbficas del darwinismo (tr. De Marga Vicedo, Salvat, Barcelona, 1987). 
tico", "esencial». Para Heidegger, Occidente, a los efectos, comienza con Platón y Aristóteles, con lo que entiende como metafísica de la presencia, en que la reflexión se centraría sobre el ser de las cosas (lo óntico) en vez de sobre la noción misma de ser (lo ontológico). De manera que la reflexión sobre el ser mismo se empieza a olvidar hasta que cae en el olvido total en la obra de Nietzsche y en su secuela más inmediata que sería la civilización científico-técnica. Pero no. Desde la visión bioantropológica todo empieza antes. Cuando el hombre se asienta y se especializa, entonces es cuando pierde el sentido global de la existencia, el sentido global de, en efecto, lo que es en origen. Se concentra en el ser derivado que le haya tocado en suerte o que haya elegido, para el caso es lo mismo, y así va perdiendo, literalmente, la conciencia del ser que es la conciencia de ser global, y al final perderá su autoconciencia. Este es el misterio del discurso de Heidegger, si misterio hay, y misterio que, en cualquier caso, deja de serlo al llegar a las últimas consecuencias del darwinismo ${ }^{60}$. Misterio del que no era consciente del todo ni el mismo profesor de Friburgo, porque su antinaturalismo se lo impedía. Antinaturalismo antinatural, valga la paradoja, porque la obra de Heidegger es profundamente biológica ${ }^{61}$. Heidegger buscaba persistentemente, y creía que había que volver a recuperar el ser, quizá en los presocráticos, en Parménides, en Heráclito, en Anaxágoras. Quizá con la ayuda de la poesía, especialmente de la poesía de Hölderlin. Pero la opacidad heideggeriana se ve clara desde un naturalismo trascendido (metanaturalismo). Sólo hay que combinar las dos ideas, naturalismo darwiniano y alarma heideggeriana y el desenlace emerge en todo su aterrador esplendor. El hombre se acaba, irremisiblemente. Desde Heidegger ese fin es la tragedia de Occidente, pero desde Darwin es, como diría el naturalista de Down en su

60 Véase asimismo mi "The ultimate epistemological consequences of the Darwinian conception", en G. MUNÉVAR (comp.), Spanish Studies in the Philosophy of Science (Kluwer, Dordrecht, 1996), pp. 153-78.

61 Como atestigua la obra relativamente reciente del especialista en Heidegger, David FARrell Krell, Daimon Life: Heidegger and Life-Philosophy (Indiana University Press, 1992), aunque a mi parecer en este texto no se aprecia del todo la auténtica contribución heideggeriana a la biología actual (véase mi Hacia una hemenéutica...), contribución que posiblemente permanece en una ambigüedad deliberada debido a las concepciones extremadamente racistas que predominaban en el entorno político-científico heideggeriano (véase p. 24 de P. LACOUELABARTHE, Heidegger, Art and Politics: The fiction of the political, tr. de C. Turner, Blackwell, Oxford, 1990). En cualquier caso, la biologización de la "propia situación" en los "tiempos que corren" es práctica bien extendida como atestigua, por ejemplo, el artículo "Identity politics in biology" de Ruth HUBBARD, capítulo 23 de Thinking about Evolution.... 
lengua materna, una «foregone conclusion», es decir, una consecuencia de suyo obvia.

En definitiva, volviendo al principio, ¿qué es el hombre? Simple y totalmente, un ser con autoconciencia. Un ser que se percibe y sabe que se percibe, que percibe y sabe que percibe. ¿Cómo apareció esa autoconciencia y con ella su "portadorn? Desde la ciencia hay varias versiones. La más verosímil, hasta la fecha, se refiere a que el homínido en sus inicios se encontró de un modo más bien súbito, geológicamente hablando, en un medio nuevo, heterogéneo, debido a la desaparición de las selvas africanas donde habitaba su anterior ser no autoconsciente. En efecto, cuando el ser vivo se halla en un medio conocido, relativamente homogéneo, no necesita autoconciencia. El comportamiento es automático. En caso contrario tiene que contemplar su posible futuro, tiene que "verlas venir». Necesita verse en su mente y simular posibles y probables actuaciones futuras. Este "verse" implica un "yo». Así pudo nacer la autoconciencia, primero incipiente, luego sería algo favorecido por la selección natural ${ }^{62}$.

Concluyendo ya, Heidegger dice que el hombre es la ventana del ser, donde asoma el ser, donde se manifiesta el ser, es como "un claro en el bosque». Pero añade Heidegger, esa ventana que se abrió en su momento, con la civilización científico-técnica se va cerrando. ¿Se cerrará del todo? En efecto, existe un paralelismo más que admirable entre esta intuición heideggeriana y el pensamiento científico al respecto, ese pensamiento denostado por el filósofo de Friburgo tal y como se ha enmarcado (Gestell). Porque lo que está haciendo el hombre por medio de la tecnología es homogeneizar su medio, de manera que la autoconciencia se está convirtiendo en un carácter orgánico obsoleto. En un mundo técnico homogéneo ya no hay necesidad de autoconciencia. Entonces se habrá cerrado la ventana del ser. ¿Para siempre? Desde la evolución darwiniana no existe el "para siemprem. Los delfines, las ballenas, fueron mamíferos terrestres que han vuelto al mar. Los osos panda, los koalas, fueron otrora carnívoros y han vuelto a un régimen herbívoro. Los ejemplos se pueden multiplicar ad nauseam. Desde Heidegger tampoco existe el "para siempre», la verdad "oculta» $\mathrm{y}$ "desoculta", los «dioses huyen y vuelven», lo que nunca sabemos es cómo, cuándo y dónde, lo que nunca sabemos, ni siquiera, es si habrá otro cómo, otro cuándo u otro dónde.

62 Para más detalles véase mi Raźn Biológica: La base evolucionista del pensamiento (Minerva, Madrid, 1999), caps.: I, II y IV. 
Sí, según dos fuentes de opinión totalmente dispares, Heidegger «que piensa" y la ciencia que "no piensa", el hombre vuelve a la animalidad. ¿Llegará del todo? ¿Volverá a salir? Éstas son preguntas que todavía se antojan remotas. Pero, por otra parte, en el mejor de los casos el hombre no ha salido del todo de la animalidad ni mucho menos, el ser se ha asomado por una ventana minúscula, simbólica se podría decir. Incluso cabría la pregunta, ¿se puede afirmar que el hombre ha salido de la animalidad? ¿Es que ha habido en algún momento una antropogénesis? Ya hemos visto que el sentido de la verdad, de la realidad, incluso de lo real, es algo efímero que destila un sabor a nadería, en el significado no coloquial del término, tanto desde la ciencia, como desde la mística. Como quizá diría Lacan, siguiendo a Derrida, el problema es que una vez fuera de Lo Real sólo se puede volver simbólicamente mediante una cascada de referentes interminable; nunca se vuelve en efecto, pero desprenderse de los símbolos es acabar con nuestra precaria humanidad. 